of a previous experiment (Zimmerman, 1969) which employed concurrent schedules of primary and conditioned reinforcement on a single lever. The present experiment provided evidence that respond. ing in the initial component of chained schedules depends upon conditioned reinforcing properties of the stimulus linking components of the chain.

REFERENCES

FERSTER, C. B., \& SKINNER, B. F. Schedules of reinforcement. New York: Appleton-CenturyCrofts, 1957
KELLEHER, R. T., \& GOLLUB, L. R. A review of positive conditioned reinforcement. Journal of the Experimental Analysis of Behavior, 1962,5, 543-597.

ZIMMERMAN, D. W. Concurrent schedules of primary and conditioned reinforcement in rats. Journal of the Experimental Analysis of Behavior, 1969, 12, 261-268.

\section{NOTE}

1. This research was supported by Grant APA-252-2057-13 from the National Research Council of Canada.

\title{
Early cold stress and emotional reactivity in BALB/c mice: A brief note on Schaefer's temperature hypothesis
}

\author{
RICHARD C. LaBARBA, ROYCE \\ HODGES, and JAN GERAGHTY, Univer- \\ sity of South Florida, Tampa, Fla. 33620
}

$B A L B / c$ mice subjected to temperatures of $10-12$ deg $C$ during the first week of life showed less emotional reactivity in an open field than did controls. It was found, however, that cold treatment of pups produces changes in maternal behavior which lead to an increase in the general stimulation level of the pups, and that this phenomenon may be confounding the data with regard to reductions in emotional reactivity.

In the course of studying the effects of early cold exposure on the response to pathogens in BALB/c mice, we had an unexpected opportunity to obtain some data on behavioral indices of emotional reactivity in a small number of mice as a function of early cold exposure. Schaefer $(1962,1963,1968)$ has presented cogent evidence that reduction in body temperature may be the basic variable in early handling phenomena. Mclver \& Camp (1966) found that Wistar rats exposed to temperatures of 3 or $7 \mathrm{deg} C$ during the first or second week of life were more active (less emotional) in an open field than were controls.

In the present study, two litters of $\mathrm{BALB} / \mathrm{c}$ mice were cold-treated by removing the mother from the litters and placing the cage in a refrigerator for $5 \mathrm{~min}$. The effect of this procedure was to reduce the internal cage temperature to approximately 10-12 deg C. The treatment was carried out for 4 days, from 2 to 5 days of age. A total of nine animals were used in the treatment group, the two litters consisting of four and five pups each. The control group of nine animals were subjected only to removal of the mother for $5 \mathrm{~min}$ a day over 2 to 5 days of age, with the cages left in the laboratory at room temperature $(72 \operatorname{deg} C)$. The control group also consisted of two litters of mice, one litter of four and one of five pups. Following treatment, all animals were weaned at 21 days of age and left undisturbed until 66 days of age. At this time, measures of activity level, quadrants traversed, and defecation were obtained during 3-min trials for 3 consecutive days in a Lehigh Valley automated open field. A mixed design analysis of variance was computed for each of the three dependent variables.

No significant differences on the measure of defecation were found between the experimental and control groups. On the measures of activity level and quadrants traversed, however, the cold-treatment group was significantly more active and mobile than controls $(\mathrm{F}=18.87, \mathrm{df}=1,16$, $p<.01 ; \quad F=20.64, \quad d f=1,16, \quad p<.01$, respectively). If one interprets these open-field measures in the typical manner, the experimental group was found to be less "emotional" than controls. That is, exposure to cold decreased emotional reactivity in these animals relative to controls. The mean number of quadrants traversed was 20.3 for controls and 33.6 for the experimental group. The means for activity level were 236.9 for controls and 309.3 for the experimental group. An interaction between treatment and days tested was found on the measure of quadrants traversed
$(\mathrm{F}=8.23, \mathrm{df}=2,32, \mathrm{p}<.01)$. Both activity measures showed a decrease from Day 1 to Day 3 of testing. No sex differences were found.

These data are generally consistent with those of McIver \& Camp (1966) insofar as they show a reduction of emotional reactivity in the open field as a function of early cold exposure, and seem to support Schaefer's temperature hypothesis. There may, however, be some confounding variables operating within cold-treatment procedures with rats and mice. In our laboratory, it was discovered that coldtreating the pups produced more or less profound reactions in the mother when she was returned to the litter. There occurs an intensification or distortion of maternal behavior patterns, characterized by a severe scattering of pups across the cage floor, frequent, random retrieval of pups, and a generally higher-than-usual amount of mother-infant interaction and stimulation. This pattern of high stimulation input for the pups may be contributing to reduction in emotional reactivity (Denenburg, 1964) since this maternal behavior pattern does not occur in the control groups. Therefore, it would appear that in early cold-stress studies there may be a resultant differential stimulation of the organisms involved, and perhaps confounding the results.

Mclver et al (1968) report findings of several other investigators in which changes in mother-pup interactions as a function of cold treatment are reported. It would appear that such observations are rather consistent, and that it now becomes necessary to carefully isolate changes in mother-infant relations from early temperature changes in assessing later behavioral changes in rats and mice.

\section{REFERENCES}

DENENBURG, V. H. Critical periods, stimulus input, and emotional reactivity: $A$ theory of infantile stimulation. Psychological Review, 1964, 71, 335-351.

McIVER, A. H., \& CAMP, B. Early cold stress: I. Effects on emotional reactivity in rats. Paper presented at the meeting of the American Psychological Association, New York, 1966.

MCIVER, A. H., JEFFREY, W. E., STEVENSON, M., \& NIELSON, H. C. Infantile handling and body temperature change in the rat: III. Early temperature change and its implications for later responses. Transactions of the New York Academy of Sciences, 1968, 30,992-1000.

SCHAEFER, T., \& TOWNE, J. C. Temperature change: The basic variable in the early handling phenomenon? Science, 1962, 135, 41-42.

SCHAEFER, T. Early "experience" and its effects on later behavioral processes in rats: 11. A critical factor in the early handling phenomenon. Transactions of the New York Academy of Sciences, 1963, 25, 871-889.

SCHAEFER, T. Infantile handling and body temperature change in the rat: 1 . Initial investigations of the temperature hypothesis. Transactions of the New York Academy of Sciences, 1968, 30, 977-984. 